\title{
BMJ Open Mitigating the mistreatment of childbearing women: evaluation of respectful maternity care intervention in Ethiopian hospitals
}

\author{
Anteneh Asefa (D) , ${ }^{1,2}$ Alison Morgan, ${ }^{2}$ Samson Gebremedhin (D) , ${ }^{3}$ Ephrem Tekle, ${ }^{4}$ \\ Sintayehu Abebe, ${ }^{5}$ Hema Magge, ${ }^{6,7,8}$ Michelle Kermode ${ }^{2}$
}

To cite: Asefa A, Morgan A, Gebremedhin S, et al. Mitigating the mistreatment of childbearing women: evaluation of respectful maternity care intervention in Ethiopian hospitals. BMJ Open 2020;10:e038871. doi:10.1136/ bmjopen-2020-038871

- Prepublication history for this paper is available online To view these files, please visit the journal online (http://dx.doi org/10.1136/bmjopen-2020038871).

Received 27 March 2020 Revised 21 July 2020 Accepted 03 August 2020

Check for updates

(C) Author(s) (or their employer(s)) 2020. Re-use permitted under CC BY-NC. No commercial re-use. See rights and permissions. Published by BMJ.

For numbered affiliations see end of article.

Correspondence to

Anteneh Asefa;

antex98@yahoo.com

\section{ABSTRACT}

Objectives There is a lack of evidence on approaches to mitigating mistreatment during facility-based childbirth. This study compares the experiences of mistreatment reported by childbearing women before and after implementation of a respectful maternity care intervention. Design A pre-post study design was undertaken to quantify changes in women's experiences of mistreatment during facility-based childbirth before and after the respectful maternity care intervention.

Intervention A respectful maternity care intervention was implemented in three hospitals in southern Ethiopia between December 2017 and September 2018 and it included training of service providers, placement of wall posters in labour rooms and post-training supportive visits for quality improvement.

Outcome measures A 25-item questionnaire asking women about mistreatment experiences was administered to 388 women (198 in the pre-intervention, 190 in the post-intervention). The outcome variable was the number of mistreatment components experienced by women, expressed as a score out of 25. Multilevel mixed-effects Poisson modelling was used to assess the change in mistreatment score from pre-intervention to postintervention periods.

Results The number of mistreatment components experienced by women was reduced by $18 \%$ when the post-intervention group was compared with the pre-intervention group (adjusted regression coefficient $(A \beta)=0.82,95 \% \mathrm{Cl} 0.74$ to 0.91). Women who had a complication during pregnancy $(A \beta=1.17,95 \% \mathrm{Cl}$ 1.01 to 1.34$)$ and childbirth $(A \beta=1.16,95 \% \mathrm{Cl} 1.03$ to 1.32) experienced a greater number of mistreatment components. On the other hand, women who gave birth by caesarean birth after trial of vaginal birth $(A \beta=0.76$, $95 \% \mathrm{Cl} 0.63$ to 0.92 ) and caesarean birth without trial of vaginal birth ( $A \beta=0.68,95 \% \mathrm{Cl} 0.47$ to 0.98$)$ experienced a lesser number of mistreatment components compared with those who had vaginal birth.

Conclusions Women reported significantly fewer mistreatment experiences during childbirth following implementation of the intervention. Given the variety of factors that lead to mistreatment in health facilities, interventions designed to mitigate mistreatment need to involve structural changes.
Strengths and limitations of this study

- This is the first study to test the effectiveness of a respectful maternity care intervention in Ethiopia.

- Comparing the counts of mistreatment components captures the diversity of mistreatment that would not have been possible by simple prevalence measures.

- Treating hospitals as random-effects controls for the impact of other interventions that may have happened around the same time in those facilities.

- Mistreatment components experienced by women were assessed using binary options (yes/no) questions which ignore multiple incidents of a mistreatment component.

- An exit survey of women is prone to recall bias in acquiring data on multiple incidents of mistreatment that would have been minimised by labour observation.

\section{INTRODUCTION}

Despite the remarkable decline in maternal mortality worldwide, around 800 women die each day due to preventable conditions that emerge in the course of pregnancy and childbirth. ${ }^{1}$ According to the World Health Organization's (WHO's) estimates, 295000 maternal deaths occurred in 2017, of which $4.7 \%$ occurred in Ethiopia. ${ }^{1}$ Low utilisation of maternal healthcare services, especially care during childbirth, is a key challenge to reducing maternal mortality. ${ }^{23}$ In 2019, only $47.5 \%$ of women gave birth in health facilities in Ethiopia. ${ }^{4}$

Women's negative experiences and/ or other women's negative experiences of facility-based childbirth are commonly reported reasons for not attending a health facility at the time of childbirth. ${ }^{5-8}$ These experiences include hostile or insensitive staff, ${ }^{7}$ disallowance of birth companions, ${ }^{67}$ disrespectful care, ${ }^{9-11}$ women's lack of autonomy, ${ }^{8}$ poor reception at health facilities, ${ }^{6}$ lack of 
privacy, ${ }^{6} 7$ unfriendly staff, ${ }^{12}$ abusive care $^{12}$ and poor readiness of health facilities. ${ }^{12}$ The attitudes, actions and system barriers that contribute to such negative experiences are nowadays labelled as mistreatment or disrespect and abuse. However, an internationally agreed definition of mistreatment or disrespect and abuse still lacks as behaviours that are acceptable to women in some contexts may be unacceptable to women in different contexts.

There is compelling evidence from many countries on the negative impact of mistreatment on the uptake of facility-based childbirth. An evidence synthesis of studies from 16 low-income and middle-income countries and China revealed that mistreatment during childbirth is a powerful deterrent to facility-based childbirth. ${ }^{13}$ Additionally, studies from Afghanistan, ${ }^{14}$ Bolivia, ${ }^{15}$ Ghana, ${ }^{16}$ Kenya, ${ }^{18}{ }^{18}$ Tanzania, ${ }^{19}$ Malawi $^{20}$ and India ${ }^{21}$ have clearly reported disrespectful care at birth as a key deterrent to facility-based childbirth.

The body of knowledge on mistreatment is still emerging and evolving, hence methodological approaches to estimate levels of mistreatment differ across settings, thereby making comparison challenging. ${ }^{22}{ }^{23}$ Prevalence studies conducted in different parts of Ethiopia between 2013 and 2017 report many examples of mistreatment ranging from non-consented care, non-confidential care, discriminatory care, abandonment of care, non-dignified care, to physical abuse during facility-based childbirth. ${ }^{24-28}$

The 2014 WHO statement, which condemns all forms of mistreatment during facility-based childbirth, identifies five actions to prevent and eliminate mistreatment globally. The statement calls for: evidence synthesis on the effectiveness of interventions that aim to improve respectful maternity care and thereby mitigate mistreatment, defining and measuring mistreatment, and inculcating service providers with the culture of respectful care at the time of birth. ${ }^{29}$ Following this, various studies, including a multi-country study led by WHO, have been conducted to review and synthesise methodological frameworks for research on mistreatment. ${ }^{13} 222330-32$ However, implementation research to assess the effectiveness of interventions to halt mistreatment have not been reported in Ethiopia.

In the move towards mitigating mistreatment, a focus on respectful maternity care is growing globally, and the 'Universal Rights of Childbearing Women' has been endorsed in several countries. ${ }^{33}$ WHO defines respectful maternity care as 'the care organized for and provided to all women in a manner that maintains their dignity, privacy and confidentiality, ensures freedom from harm and mistreatment, and enables informed choice and continuous support during labour and childbirth', ${ }^{34}$

With the aim of meeting the maternal mortality targets of the sustainable development goals, strategies for ending preventable maternal mortality were introduced in 2015. The strategy calls for health systems not to neglect respectful maternity care while endeavouring to deliver effective clinical interventions. ${ }^{35}$ WHO's framework for quality maternal and newborn healthcare reinforces the important role of respectful maternity care, and identifies respect and preservation of dignity as one of the eight domains of quality of care ${ }^{36}$ Additionally, in 2018, WHO released guidelines for a positive childbirth experience which recommend respectful maternity care throughout labour and birth for all women. ${ }^{34}$ A recent WHO paper published in The Lancet that found high levels of mistreatment in four countries also highlighted the need for an urgent action to promote the provision of respectful maternity care worldwide. ${ }^{37}$

The government of Ethiopia launched a national movement entitled 'the caring, respectful and compassionate health workforce' in 2016. The initiative is one of the four health sector transformation agendas aiming to achieve health targets set for the 5 years between 2015/2016 and 2020/2021. ${ }^{38}$ However, respectful maternity care initiatives are in early-stage development and currently limited to a few pilot health facilities and technically supported by international partner organisations. Consequently, there is an evidence gap regarding implementation of effective respectful maternity care interventions in the country.

This study was undertaken to assess women's experiences of mistreatment during facility-based childbirth before and after implementation of an intervention that was designed to improve the quality of care women receive during childbirth in hospitals. Previous respectful maternity care intervention studies from Kenya ${ }^{39}$ and Tanzania ${ }^{40}{ }^{41}$ revealed a significant reduction in the level of mistreatment and an improved attitude of service providers towards women, as a consequence of the interventions. This study is part of a broader interventional mixed methods study that aimed to identify health system challenges to the implementation of respectful maternity care and potential solutions to address these challenges. Lessons drawn from the respectful maternity care training and its implementation ${ }^{42}$ and health system constraints to the promotion of respectful maternity care in Ethiopian hospitals are reported elsewhere. To our knowledge, this study is the first to report on the effectiveness of a respectful maternity care intervention in Ethiopia. The study findings add weight to the emerging evidence base on respectful maternity care, and will be used to inform planning and decision making concerning maternal health and other related services in Ethiopia.

\section{MATERIALS AND METHODS \\ Study setting}

This study was undertaken in three hospitals located in the Southern Nations Nationalities and Peoples Region (SNNPR), Ethiopia. Health services in Ethiopia are organised in three tiers: health posts, health centres and primary hospitals are in the first tier; the second tier consists of general hospitals; and the third tier, specialised hospitals. ${ }^{38}$ In principle, general hospitals are designed to serve a catchment population of 1-1.5 million people whereas primary hospitals are expected to serve 60000-100000 people. One of the study hospitals, Leku, is a primary 
hospital reported to be serving a catchment population of 261271 including an estimated 8000 women who give birth each year. The other two hospitals, Adare and Yirgalem, are general hospitals serving a catchment population of 359358 and 267589 , respectively. An estimated 10000 and 9000 pregnant women give birth each year in the catchments of Adare and Yirgalem hospitals, respectively. The hospitals were selected purposively taking into consideration their geographical proximity and their varying level in the tiers of the Ethiopian health system. The intervention involved only these three hospitals. None of hospitals have a private labour ward or birthing room which means that several women labour in the same room and give birth in one birthing room.

\section{Study design}

This study is part of a mixed methods implementation research study that was conducted to identify health system constraints to the promotion of respectful maternity care and to develop and assess mitigation approaches. A pre-post study that involved no comparison group was undertaken between December 2017 and September 2018 to quantify changes in women's experiences of mistreatment during facility-based childbirth. Women who gave birth in the study hospitals were surveyed at the time of discharge; the pre-intervention surveys were conducted in March 2018, whereas the post-intervention surveys were conducted in July and August 2018.

\section{Description of the intervention}

The intervention included: training of service providers, placement of wall posters in labour rooms and posttraining supportive visits for quality improvement. Each of these are described later.

The training of service providers involved a 3-day workshop using a respectful maternity care training manual developed for this intervention. The manual was drafted by maternal health researchers from Ethiopia and Australia after review of previous respectful maternity care training manuals designed for low-income settings $\left(\right.$ Kenya ${ }^{43}$ Tanzania $^{44}$ and Nigeria ${ }^{45}$ ), international human rights declarations, ${ }^{334647}$ national professional codes of ethics and national training manuals on maternity care and quality improvement. The manual includes an overview of maternal health in Ethiopia. It covers topics such as human rights and law in the context of reproductive health, respectful maternity care rights and standards, professional ethics, and continuous quality improvement. The draft manual was reviewed by three senior maternal health experts at the Federal Ministry of Health and SNNPR Health Bureau for its content and applicability in the Ethiopian context. Two rounds of 3-day respectful maternity care training sessions were conducted at Hawassa University Comprehensive Specialized Teaching Hospital. The training was interactive and deployed various teaching methods including presentations, role plays, demonstrations, case studies, individual readings, video shows and a hospital visit. Training sessions were facilitated by the principal investigator, a senior maternal health expert from the SNNPR Health Bureau and a senior obstetrician-gynaecologist. A total of 64 health service providers participated in the training, 33 in the first round and 31 in the second round (all were staff from the participating hospitals). Fifty-two were midwives, whereas the remaining were integrated emergency surgical officers (4), general practitioners (3), nurses (3) and health officers (2). The SNNPR Health Bureau and hospital administrations communicated their expectation that all service providers at the participating hospitals who assist women during childbirth should attend the training. In reality, all eligible service providers from Adare (26) and Leku (21) hospitals attended the training sessions. Five among the 22 eligible service providers from Yirgalem hospital did not attend the training sessions for personal reasons.

Five types of wall posters (four in English and one in Amharic) were distributed to the hospitals following completion of the service provider training. The posters were displayed in labour wards and waiting rooms to serve as job aids for service providers who are trained in English to become health professionals and who generally use service guidelines and reporting formats prepared in English. One of the English version wall posters lists the universal rights of childbearing women prepared by the White Ribbon Alliance. ${ }^{33}$ The remaining three are infographics taken from the intrapartum care for a positive childbirth experience guideline prepared by the WHO. ${ }^{34}$ The Amharic version poster described the manifestations of mistreatment during facility-based childbirth and the universal rights of childbearing women endorsed by the Federal Ministry of Health, Ethiopia.

Two rounds of post-training quality improvement supportive supervision visits were conducted by the principal investigator and a senior maternal health expert in all hospitals at 2-week intervals, in June and July of 2018. During the initial visit, a facility-led assessment of maternity care settings was conducted using a structured checklist that was part of the health providers' training (online supplementary file 1 ). The checklist included 32 respectful maternity care standards that were assessed using observation, interview, and review of documents; the standards were grouped into five categories. Action plans were developed by service providers to address actionable gaps identified by the respectful maternity care standards assessment. The gaps that could not be addressed at the labour ward level were passed to hospital administrators for further actions (online supplemental file 1). During the second visit, similar steps were undertaken to see changes as a result of the initial action plan and promote continuous quality improvement as a routine process. Detailed information on the sequencing of the interventions and the timing of data collection for the broader study, including the current study, is appended (online supplemental file 2). 


\section{Participants and procedures}

Pregnant women who gave birth in the study hospitals were eligible for inclusion in the study regardless of their mode of birth (natural or operative) or birth outcome. Once women had completed their discharge requirements and procedures, they were invited to participate in the study and were consecutively enrolled until the required sample size was achieved for each study hospital.

\section{Sample size and sampling}

Stata V.14 software was used to calculate the sample size for this study using the menu option for determining the difference between two sample means with the assumption of: an anticipated mean count of mistreatment experiences women face in facility-based childbirth (preintervention) of 4.91, taken from a study conducted in Addis Ababa ${ }^{26}$; an anticipated mean count of mistreatment experiences women face in facility-based childbirth (post-intervention) of 3.96 (mean difference of 0.95); statistical power of $90 \%$; an allocation ratio of $1: 1$ between the pre-intervention and post-intervention groups; 0.05 level of significance; and 10\% non-response rate. Additionally, women receiving care in the same hospital are more likely to receive comparable care during childbirth, so the sample size was adjusted for clustering by assuming a clustering effect of 2 . With these assumptions, the minimum required sample size was calculated to be 378 (189 in the pre-intervention group and 189 in the post-intervention group). Eventually, 392 women were invited and 388 women were surveyed (190 in the preintervention and 198 in the post-intervention) making the response rate $98.9 \%$; rushing to go home and lack of interest to participate were the reasons for nonparticipation. Allocation of samples to the three hospitals was made proportionately depending on the number of women who gave birth in the hospitals in the last quarter of 2017 for the pre-intervention survey, and the second quarter of 2018 for the post-intervention survey. Accordingly, 172 (87 pre-intervention, 85 post-intervention) women were surveyed from Adare hospital, whereas 86 (46 pre-intervention, 40 post-intervention) and 130 (65 pre-intervention, 65 post-intervention) were from Leku and Yirgalem hospitals, respectively. Eligible women were enrolled into the study consecutively until the required sample size was met.

\section{Variables and outcome measures}

The survey included 25 questions about women's experiences of childbirth in the study hospitals (table 1). The questions pertained to six categories: verbal abuse; physical abuse; non-consented care; lack of information, privacy and confidentiality; neglect and discrimination; and refusal of preference. The responses consisted of dichotomised mutually exclusive options set as 'yes' or 'no'. The outcome variable was a count variable computed from the 25 variables clustered into the categories mentioned earlier; the number of mistreatment components women experienced were counted as a score out of 25; maximum possible score being 25 and minimum 0 .

The main independent variable of the study was whether the woman belongs to the pre-intervention group or the post-intervention group, that is, whether she was hospitalised before or after the intervention. The other independent variables, that is, potential confounders that were considered for adjustment were: sociodemographic (place of residence, age, age at first marriage, marital status, educational status, occupation, religion, ethnicity, monthly income, number of children); obstetric characteristics (complication/s during pregnancy and childbirth, type of birth, intervention/s for vaginal birth); service utilisation history (antenatal visits, history of facility-based childbirth); service-related (referral status, time of admission, hours of stay, gender of service provider).

\section{Questionnaire development}

The survey questionnaire was developed as per the recommendations of a comparative analysis of five prevalence studies of mistreatment that were conducted in sub-Saharan Africa countries, including Ethiopia. ${ }^{22}$ Additionally, the typology suggested by a mixed methods systematic review on mistreatment during facility-based childbirth ${ }^{23}$ was used to refine and group the 25 questions with some modifications. The questionnaire was originally prepared in English and later translated into both Amharic and Sidamu Afo languages and back-translated to check for consistency (online supplemental file 3). Subsequently, an electronic data collection template was prepared using the KoBoToolbox tool, and data collection was made using the KoBoCollect app for android devices.

\section{Data collection}

Data were collected by trained nurses and midwives who were fluent speakers of both Amharic and Sidamu Afo languages, recruited from Hawassa University Comprehensive Specialized Hospital. Data collectors received detailed 3-day training on the purpose of the study, contents of the questionnaire and effective and ethical survey administration. The questionnaire was pretested on 15 women who gave birth in Hawassa University Comprehensive Specialized Hospital which resulted in minor modifications to the questionnaire. Before conducting the post-intervention survey, data collectors received a 1 day refresher training. To ensure data quality, the supervisor reviewed completed questionnaires for key contents before they were uploaded from the tablets to the server; the principal investigator cross-checked all uploaded questionnaires for consistency and completeness.

\section{Data management and analysis}

Data were exported to SPSS V.24 software for cleaning and later to StataSE V.15 software for analysis. The outcome variable, number of mistreatment components women experienced, was confirmed to follow the 
Table 1 Women's experience of mistreatment during childbirth

\begin{tabular}{|c|c|c|c|}
\hline Types of mistreatment experienced & $\begin{array}{l}\text { Pre-intervention } \\
\mathrm{n}(\%)\end{array}$ & $\begin{array}{l}\text { Pos-tintervention } \\
\text { n (\%) }\end{array}$ & $\begin{array}{l}\text { P value } \\
\text { for } \chi^{2}\end{array}$ \\
\hline Verbal abuse & $17(8.6)$ & $11(5.8)$ & 0.29 \\
\hline Health workers used harsh or rude language & $8(4.0)$ & $6(3.2)$ & 0.64 \\
\hline $\begin{array}{l}\text { Health workers made judgmental or accusatory comments about } \\
\text { woman }\end{array}$ & $8(4.1)$ & $2(1.1)$ & 0.06 \\
\hline Health workers made threats of withholding treatment & $1(0.5)$ & $2(1.1)$ & 0.54 \\
\hline Health workers blamed woman for any features of birth outcome & $4(2.0)$ & $4(2.1)$ & 0.95 \\
\hline Physical abuse & $33(16.7)$ & $17(8.9)$ & $0.02^{*}$ \\
\hline Woman was beaten, slapped, kicked or pinched & $7(3.5)$ & $5(2.6)$ & 0.61 \\
\hline Woman was gagged & $19(9.6)$ & $11(5.8)$ & 0.16 \\
\hline Woman was restrained & $19(9.6)$ & $9(4.74)$ & 0.06 \\
\hline Non-consented care & $165(83.3)$ & $124(65.3)$ & $<0.001^{*}$ \\
\hline Health workers did not obtain consent for procedure/s & $138(69.7)$ & $84(44.2)$ & $<0.001^{*}$ \\
\hline Health workers ever separated woman from her baby without explaining & $14(7.1)$ & $7(3.7)$ & 0.14 \\
\hline $\begin{array}{l}\text { Health workers did not ask woman's permission before conducting } \\
\text { vaginal examination }\end{array}$ & $128(64.7)$ & $91(47.9)$ & $0.001^{*}$ \\
\hline $\begin{array}{l}\text { Health workers did not ask woman's permission before performing } \\
\text { surgery (episiotomy or caesarean section) }(n=220)\end{array}$ & $69(65.1)$ & $44(38.6)$ & $<0.001^{*}$ \\
\hline Health workers made woman stay in the hospital against her will & $4(2.0)$ & $2(1.1)$ & 0.44 \\
\hline Lack of information, privacy and confidentiality & $189(95.5)$ & $182(95.8)$ & 0.88 \\
\hline Health workers did not keep woman's information confidential & $18(9.1)$ & $7(3.7)$ & $0.03^{*}$ \\
\hline $\begin{array}{l}\text { Health workers conducted vaginal examination without maintaining } \\
\text { woman's privacy }\end{array}$ & $162(81.8)$ & $147(77.4)$ & 0.28 \\
\hline Health workers did not give periodic updates on woman's labour & $104(52.5)$ & $129(67.9)$ & $0.002^{*}$ \\
\hline $\begin{array}{l}\text { Health workers spoke to woman in a language she could not } \\
\text { understand }\end{array}$ & $5(2.5)$ & $9(4.7)$ & 0.24 \\
\hline Neglect and discrimination & $24(12.1)$ & $17(8.9)$ & 0.31 \\
\hline Health workers did not always come following woman's call & $8(4.0)$ & $7(3.7)$ & 0.86 \\
\hline Woman was ever left for a prolonged period of time without attention & $19(9.6)$ & $12(6.3)$ & 0.23 \\
\hline Health worker was not present for the actual birth of woman's baby & $5(2.5)$ & $3(1.6)$ & 0.51 \\
\hline Health workers discriminated woman based on her attribute & - & $2(1.1)$ & - \\
\hline Refusal of preference & $134(67.7)$ & $104(54.7)$ & $0.01^{*}$ \\
\hline Health workers did not allow woman to have a birth companion present & $64(86.5)$ & $18(69.2)$ & $0.04^{*}$ \\
\hline Health workers did not allow woman to move around during labour & $43(76.7)$ & $63(94.3)$ & $0.002^{*}$ \\
\hline Health workers did not allow woman to have foods or fluids & $66(94.3)$ & $62(98.4)$ & 0.21 \\
\hline $\begin{array}{l}\text { Health workers did not allow woman to give birth in her preferred } \\
\text { position }\end{array}$ & $43(66.2)$ & $12(33.3)$ & $0.001^{*}$ \\
\hline Health workers did not allow woman to have cultural practice in labour & $16(76.2)$ & $0(-)$ & - \\
\hline
\end{tabular}

Poisson distribution by using a one sample independent Kolmogorov-Smirnov test $(\mathrm{p}=0.97)$. Additionally, the mean (4.40) and variance (4.14) of the outcome variable were found to be close and thus suitable for Poisson modelling. Three models were constructed in this study: a null (intercept-only) model with the intercept as a fixed effect and random effects for hospitals (model I); a model containing the intervention as a fixed effect and random effects for hospitals (model II); and a model containing the intervention, sociodemographic, obstetric and health service-related factors as fixed effects and random effects for hospitals (model III). The independent variables were checked for multicollinearity using the variance inflation factor. Hospital was set as a random-effects variable in all models to take into account the likely absence of independence among women who received care from the same hospital. Analysis results from model III are reported in this study. A multilevel mixed effects Poisson regression analysis was conducted to identify the association between the independent and outcome variables while adjusting 
for possible confounders. The fixed effects (association measures) and random effects (variation measures) for the number of mistreatment components experienced are reported. Adjusted exponentiated regression coefficients $(\beta)$ with their corresponding $95 \%$ CIs were used to estimate the level of association between independent variables and the outcome variable. For comparison purpose, we also ran a fixed effects model with robust standard errors which included hospitals along with other variables of model III as fixed effects.

\section{Patient involvement}

Women who gave birth in the study hospitals during the survey periods were involved in the study. These women were not involved in research design, tool development, data analysis and reporting.

\section{RESULTS \\ Demographics}

Among the 388 women who participated in the study (198 pre-intervention, 190 post-intervention), there was no difference in the distribution of place of residence, age, age at first marriage, educational level, marital status, religion and ethnicity between the two groups (table 2). Illiteracy and having a regular monthly income were higher in the post-intervention group. More than two-thirds

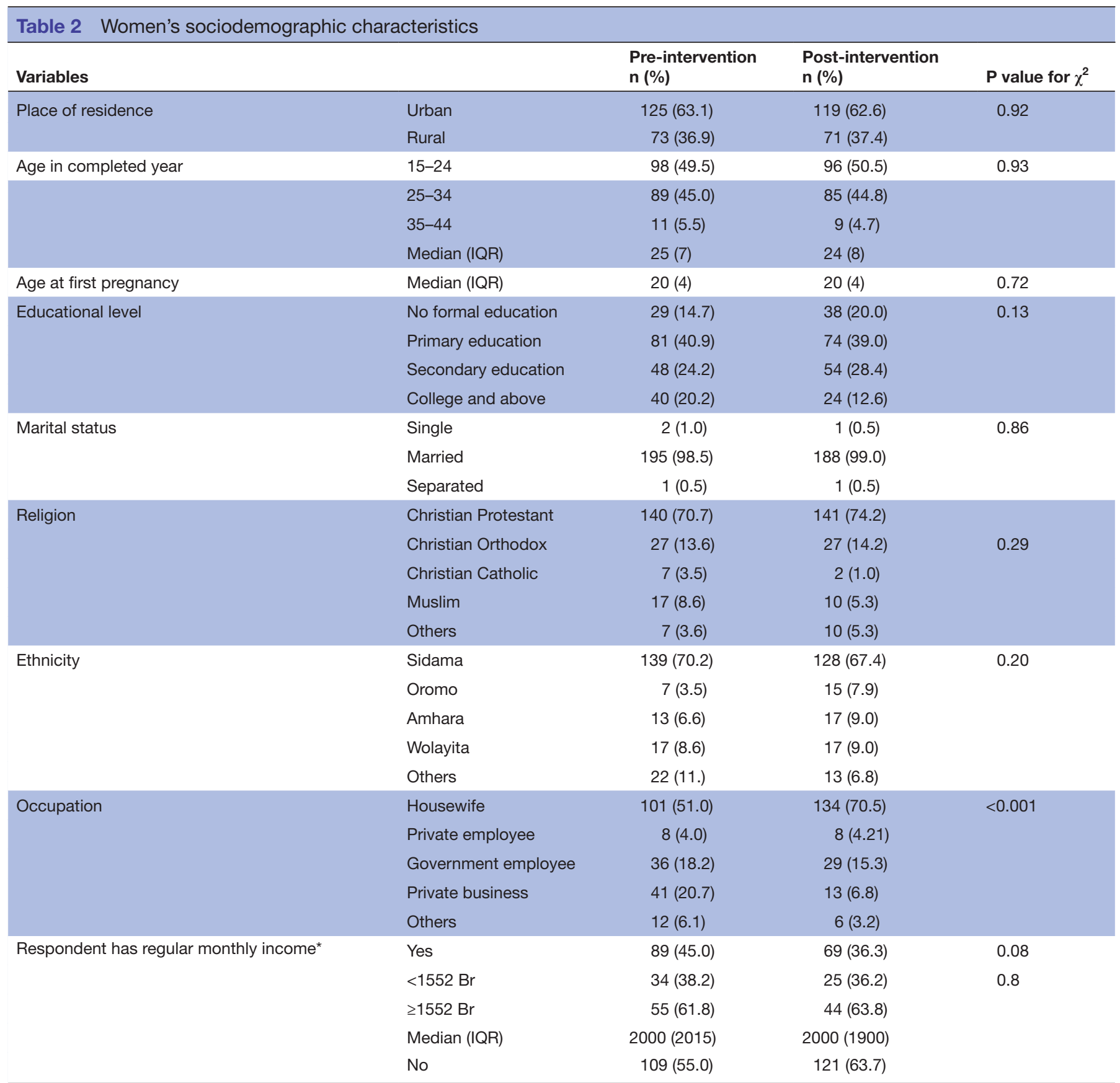

*US\$1=27.23 Br (average between March and August 2018). 
$(70.5 \%)$ of women in the post-intervention group were housewives compared with $51 \%$ in the pre-intervention group, $\mathrm{p}<0.001$ (table 2).

\section{Obstetric characteristics}

More than half of the participants in the pre-intervention $(55.6 \%)$ and post-intervention $(51.6 \%)$ groups were multiparous (table 3 ). The majority of women gave birth to their previous child at a health institution, $75.2 \%$ in the pre-intervention and $70.1 \%$ in the post-intervention group. Comparable levels of women in both groups had antenatal visits during their index pregnancy; however, having three or more antenatal visits was higher among women in the pre-intervention survey $(82.4 \%$ vs $71.2 \%$; $\mathrm{p}=0.04$ ). Complications during the index pregnancy were reported by $17.2 \%$ of women in the pre-intervention group and $10 \%$ in the post-intervention group $(\mathrm{p}=0.04)$. Compared with women in the pre-intervention group, women in the post-intervention group were less likely to have had a vaginal birth $(77.4 \%$ vs $87.9 \%, \mathrm{p}=0.01)$ or an intervened vaginal birth $(39.5 \%$ vs $46.4 \%, \mathrm{p}=0.15)$ (table 3).

\section{Service characteristics}

There was no difference between the pre-intervention and post-intervention groups with respect to referral status and time of admission (table 3). On the other hand, a higher proportion $(52.5 \%)$ of women in the preintervention group gave birth during the night-time than their counterparts $(42.6 \%), \mathrm{p}=0.05$. More than threefifths $(61.1 \%)$ of women in the pre-intervention group were assisted mainly by female service providers $(51.6 \%$ in post-intervention group, $\mathrm{p}=0.06$ ) (table 3 ).

\section{Preference during childbirth}

There were $86(43.7 \%)$ women in the pre-intervention group who wanted to have a birth companion in the labour ward, while the proportion was only $17.9 \%$ in the post-intervention group $(\mathrm{p}<0.001)$. Among those women who wanted to have a birth companion in the pre-intervention group, $14 \%$ were afraid to ask service providers to have one $(23.5 \%$ in the post-intervention group). A higher proportion of women in the preintervention group wanted to adopt a preferred birthing position $(34.9 \%$ vs $19.1 \%, \mathrm{p}<0.001)$ and cultural practice in the labour ward $(21.7 \%$ vs $8.9 \%, \mathrm{p}=0.001)$. Additionally, more than half $(51.2 \%)$ of women who wanted to have cultural practice in the pre-intervention group were afraid to ask service providers to have the practice ( $47.1 \%$ in the post-intervention group). The proportion of women who wanted to move around during birth and who wanted to have food or fluids during birth did not vary significantly between the two groups (table 3).

\section{Experiences of mistreatment}

Almost all women (99.5\% pre-intervention vs 99\% postintervention group) reported experiencing at least one type of mistreatment. The number of mistreatment types experienced ranged from 1 to 12 in the pre-intervention group (median=5), and 1 to 11 in the post-intervention group (median=3.5).

When the pre-intervention and post-intervention groups are compared, a number of improvements are evident. Vaginal examination was performed without permission for $47.9 \%$ of the women in post-intervention group; $64.7 \%$ in pre-intervention group $(\mathrm{p}=0.001)$ (table 1). Additionally, seeking women's consent before procedures, and the practice of allowing birth companions improved post-intervention. On the other hand, some aspects of mistreatment such as the use of harsh or rude language against women, gagging women and leaving women for a prolonged period of time without attention did not improve significantly following the staff training. Additionally, more than two-thirds (67.9\%) of women in the post-intervention group claimed that service providers did not give periodic updates on their labour $(52.5 \%$ in the pre-intervention survey; $\mathrm{p}=0.002$ ) (table 1).

We also compared the proportion of women who had encountered mistreatment grouped by six categories (verbal abuse; physical abuse; non-consented care; lack of information, privacy and confidentiality; neglect and discrimination; and refusal of preference). Women who reported having experienced at least one type of mistreatment in a given category were regarded as mistreated in that category. The level of non-consented care measured after the intervention $(65.3 \%)$ is lower than before the intervention (83.3\%), $\mathrm{p}<0.001$ (table 1). Similarly, experiences of physical abuse and refusal of preference showed improvement after the intervention. No significant difference was detected in the level of the remaining three categories of mistreatment (table 1).

\section{Factors associated with the number of mistreatment components experienced}

In the bivariate analysis, the number of mistreatment components experienced was higher among women who had a complication during the index childbirth $(\mathrm{C} \beta=1.16,95 \% \mathrm{CI} 1.05$ to 1.30$)$ and an intervention for vaginal birth (C $\beta=1.31,95 \%$ CI 1.20 to 1.44$)$ (table 4$)$. Women who gave birth in Yirgalem hospital also experienced a higher number of mistreatment components $(\mathrm{C} \beta=1.36,95 \% \mathrm{CI} 1.22$ to 1.51$)$ compared with those who gave birth in Adare hospital. In contrast, the number of mistreatment components experienced was lower among women who had two or more births and women who had a caesarean birth (table 4).

\section{Multilevel analysis of changes in reported components of mistreatment}

Outputs of the intercept-only model (model I) showed that there was significant variation between hospitals in the number of components of mistreatment experienced by women (table 4). The intraclass correlation coefficient (ICC) of model I also revealed that $12.3 \%$ of the variation in the number of components of mistreatment experienced by women is attributable 
Table 3 Women's obstetric and maternal healthcare characteristics and preferences during childbirth

\begin{tabular}{|c|c|c|c|c|}
\hline Variables & & $\begin{array}{l}\text { Pre-intervention } \\
\mathrm{n}(\%)\end{array}$ & $\begin{array}{l}\text { Post-intervention } \\
\text { n (\%) }\end{array}$ & $\begin{array}{l}\text { P value } \\
\text { for } \chi^{2}\end{array}$ \\
\hline \multirow[t]{3}{*}{ Total number of births } & One & $88(44.4)$ & $92(48.4)$ & 0.43 \\
\hline & Two or more & $110(55.6)$ & $98(51.6)$ & \\
\hline & Median (IQR) & $2(1)$ & $2(2)$ & \\
\hline \multirow[t]{2}{*}{ Place of birth of previous child $(n=206)$} & Health facility & $82(75.2)$ & $68(70.1)$ & 0.41 \\
\hline & Outside health facility & $27(24.8)$ & $29(29.9)$ & \\
\hline \multirow{4}{*}{$\begin{array}{l}\text { Number of previous facility-based } \\
\text { childbirths }\end{array}$} & None & $22(20.2)$ & $22(22.5)$ & \\
\hline & One & $69(63.3)$ & $53(54.0)$ & \\
\hline & Two and more & $18(16.5)$ & $23(23.5)$ & \\
\hline & Median (IQR) & $1(0)$ & $1(0)$ & \\
\hline \multirow[t]{5}{*}{ Antenatal visit during index pregnancy } & Yes & $188(94.9)$ & $184(96.8)$ & 0.35 \\
\hline & One & $5(2.7)$ & $9(4.9)$ & 0.04 \\
\hline & Two & $28(14.9)$ & $44(23.9)$ & \\
\hline & Three or more & $155(82.4)$ & $131(71.2)$ & \\
\hline & No & $10(5.1)$ & $6(3.2)$ & \\
\hline \multirow{2}{*}{$\begin{array}{l}\text { Experienced complication during index } \\
\text { pregnancy }\end{array}$} & Yes & $34(17.2)$ & $19(10.0)$ & 0.04 \\
\hline & No & $164(82.8)$ & $171(90.0)$ & \\
\hline \multirow{2}{*}{$\begin{array}{l}\text { Experienced complication during index } \\
\text { childbirth }\end{array}$} & Yes & $67(34.0)$ & $70(36.8)$ & 0.56 \\
\hline & No & $130(66.0)$ & $120(63.2)$ & \\
\hline \multirow[t]{2}{*}{ Referral status on admission } & Referred & $81(40.9)$ & $86(45.3)$ & 0.39 \\
\hline & Non-referred & $117(59.1)$ & $104(54.4)$ & \\
\hline \multirow[t]{2}{*}{ Time of admission* } & Day time & $106(53.5)$ & $99(52.1)$ & 0.78 \\
\hline & Night-time & $92(46.5)$ & $91(47.9)$ & \\
\hline \multirow[t]{2}{*}{ Time of birth* } & Day time & $94(47.5)$ & $109(57.4)$ & 0.05 \\
\hline & Night-time & $104(52.5)$ & $81(42.6)$ & \\
\hline \multirow[t]{3}{*}{ Type of birth } & Vaginal birth & $174(87.9)$ & $147(77.4)$ & 0.01 \\
\hline & $\begin{array}{l}\text { Caesarean after trial of } \\
\text { vaginal birth }\end{array}$ & $18(9.1)$ & $38(20.0)$ & \\
\hline & $\begin{array}{l}\text { Caesarean without trial of } \\
\text { vaginal birth }\end{array}$ & $6(3.0)$ & $5(2.6)$ & \\
\hline \multirow{2}{*}{$\begin{array}{l}\text { Had intervention/s for vaginal birth } \\
(\mathrm{n}=377) \dagger\end{array}$} & Yes & $89(46.4)$ & $73(39.5)$ & 0.15 \\
\hline & No & $101(53.6)$ & $111(60.5)$ & \\
\hline \multirow[t]{3}{*}{ Types of assisted vaginal birth $(n=162) \ddagger$} & Vacuum extraction & $12(13.5)$ & $9(12.3)$ & 0.83 \\
\hline & Forceps delivery & $8(9.0)$ & $2(2.7)$ & 0.10 \\
\hline & Episiotomy & $82(92.1)$ & $71(97.3)$ & 0.16 \\
\hline \multirow[t]{2}{*}{ Gender of main service provider } & Female & $121(61.1)$ & $98(51.6)$ & 0.06 \\
\hline & Male & 77 (38.9) & $92(48.4)$ & \\
\hline \multirow{2}{*}{$\begin{array}{l}\text { Woman wanted to have birth companion } \\
\text { in the labour ward }\end{array}$} & Yes & $86(43.7)$ & $34(17.9)$ & $<0.001$ \\
\hline & No & $111(56.5)$ & $156(82.1)$ & \\
\hline \multirow{2}{*}{$\begin{array}{l}\text { Woman wanted to move around during } \\
\text { birth }\end{array}$} & Yes & $57(28.8)$ & 67 (35.5) & 0.16 \\
\hline & No & $141(71.1)$ & $122(64.5)$ & \\
\hline \multirow{2}{*}{$\begin{array}{l}\text { Woman wanted to have food or fluids } \\
\text { during birth }\end{array}$} & Yes & $70(35.4)$ & $63(33.2)$ & 0.65 \\
\hline & No & $128(64.6)$ & $127(66.8)$ & \\
\hline \multirow[t]{2}{*}{ Woman had a preferred birthing position } & Yes & 69 (34.9) & $36(19.1)$ & $<0.001$ \\
\hline & No & $129(65.1)$ & 153 (80.9) & \\
\hline
\end{tabular}


Table 3 Continued

\begin{tabular}{llccc}
\hline Variables & & $\begin{array}{l}\text { Pre-intervention } \\
\mathbf{n}(\%)\end{array}$ & $\begin{array}{l}\text { Post-intervention } \\
\mathbf{n}(\%)\end{array}$ & $\begin{array}{l}\text { P value } \\
\text { for } \chi^{2}\end{array}$ \\
\hline $\begin{array}{l}\text { Woman wanted to have cultural practice } \\
\text { in labour }\end{array}$ & Yes & $43(21.7)$ & $17(8.9)$ & 0.001 \\
& No & $155(78.3)$ & $173(91.1)$ & \\
\hline
\end{tabular}

${ }^{*}$ A woman can have more than one procedure.

†Stayed in hospital for at least two hours between 20:00 and 08:00 immediately before childbirth.

†Includes: episiotomy, vacuum extractor or forceps.

to differences across hospitals. Model II, a model with the main independent variable (intervention group), was different and fit as compared with model I ( $p$ for likelihood ratio (LR) test $<0.001)$. Furthermore, model III (a model that includes all the independent variables and the intervention group) was different and fit as compared with model II ( $p$ for LR test $<0.001$ ). The ICC of model III shows a lower variation $(9 \%)$ between the hospitals than models I and II. Model III displays the changes in the number of components of mistreatment experienced by participants of the two groups (preintervention and post-intervention) after adjusting for potential confounders.

As displayed in table 4, the number of components of mistreatment experienced by women in the postintervention group is lower by $18 \%$ than those in the pre-intervention group; adjusted regression coefficient $(\mathrm{A} \beta)=0.82,95 \%$ CI 0.74 to 0.91 . The fixed effects model with hospitals as predictors yielded the same effect size with a narrower $\mathrm{CI}$ ( $\mathrm{A} \beta=0.82,95 \%$ CI 0.76 to 0.89 ).

The number of components of mistreatment experienced by women was higher among women with complications during pregnancy $(\mathrm{A} \beta=1.17,95 \% \mathrm{CI}$ 1.01 to 1.34$)$ or childbirth $(\mathrm{A} \beta=1.16,95 \% \mathrm{CI} 1.03$ to 1.32). Women who gave birth by caesarean section after trial of vaginal birth $(\mathrm{A} \beta=0.76,95 \% \mathrm{CI} 0.63$ to 0.92 ) and by caesarean section without trial of vaginal birth ( $\mathrm{A} \beta=0.68,95 \%$ CI 0.47 to 0.98 ) experienced fewer number of mistreatment components. The number of mistreatment components experienced by women did not significantly vary by women's demographic, servicerelated or other obstetric characteristics not already mentioned earlier (table 4).

\section{DISCUSSION}

This study was conducted as part of a mixed methods implementation research that aims to identify health system barriers to respectful maternity care and to propose and test mitigation approaches. To our knowledge, this study is the first to report on the effectiveness of a respectful maternity care intervention (facilitylevel) in Ethiopia. The study found that the number of mistreatment components experienced by women after the respectful maternity care intervention was reduced by $18 \%$ compared with the number experienced by women before the intervention. This is a notable improvement given the small-scale intervention we implemented and the known limitations of interventions focused primarily on training health workers. ${ }^{48}$ Training of service providers alone cannot be a solution to address mistreatment unless other system elements that significantly influence the behaviour of service providers are also addressed.

Similar implementation studies have been conducted in response to the growing attention to mistreatment and the need to identify recommendations to eliminate mistreatment. The Heshima study (Kenya) ${ }^{39}$ and the Staha study (Tanzania) ${ }^{41}$ were conducted to assess the impact of respectful maternity care interventions on the level of mistreatment. The Heshima study involved a multi-component respectful maternity care intervention (policy, facility and community level); $7 \%$ reduction in the prevalence of mistreatment was reported following the intervention. ${ }^{39}$ The Staha study involved community level (client service charter) and facility-level (quality improvement inventory and intervention in maternity wards) interventions, and reported a $66 \%$ reduction in the odds of women reporting mistreatment after the intervention. ${ }^{41}$ Both Heshima and Staha studies used a prevalence measure of mistreatment; women who faced at least one form of mistreatment were labelled as mistreated. Considering women who encountered at least one form of mistreatment as mistreated in these studies may have resulted in the underestimation of the magnitude of change.

In this study, the proportion of women who experienced non-consented care, physical abuse and refusal of preference was significantly lower in the post-intervention group. No significant difference was observed in the proportion of women who experienced mistreatment in the remaining three categories of mistreatment (verbal abuse; lack of information, privacy and confidentiality; and neglect and discrimination). The very high proportion of women who reported 'non-consented care' suggests that the issue of obtaining consent is not well understood by the staff (and probably by the hospital administration also). Similarly, the very high proportion of women who reported 'lack of information, privacy and confidentiality' and 'refusal of preferences' suggests a poor understanding of these concepts and rights among providers. These are areas that need to be integrated and foregrounded into professional development/quality 
Open access

Table 4 Multilevel mixed-effects regression of counts of mistreatment experienced by women

\begin{tabular}{|c|c|c|c|c|}
\hline & Bivariate model & Model I & Model II & Model III \\
\hline Variables & $\mathrm{C} \beta(95 \% \mathrm{Cl})$ & $\mathrm{A} \beta(95 \% \mathrm{Cl})$ & $\mathrm{A} \beta(95 \% \mathrm{Cl})$ & A $\beta(95 \% \mathrm{Cl})$ \\
\hline \multicolumn{5}{|l|}{ (A) Fixed effects } \\
\hline \multicolumn{5}{|l|}{ Intervention group } \\
\hline Pre-intervention & Ref. & & Ref. & Ref. \\
\hline Post-intervention & $0.79(0.72$ to 0.87$)$ & & $0.79(0.72 \text { to } 0.87)^{*}$ & $0.82(0.74 \text { to } 0.91)^{*}$ \\
\hline Urban & Ref. & & & Ref. \\
\hline Rural & 1.11 (1.00 to 1.22$)$ & & & 1.05 (0.93 to 1.19$)$ \\
\hline \multicolumn{5}{|l|}{ Age in completed year } \\
\hline $15-24$ & Ref. & & & Ref. \\
\hline $25-34$ & $0.85(0.77 \text { to } 0.94)^{*}$ & & & 0.95 (0.82 to 1.09$)$ \\
\hline Single & Ref. & & & Ref. \\
\hline Married & 0.77 (0.48 to 1.25$)$ & & & 0.79 (0.45 to 1.39$)$ \\
\hline Separated & 1.24 (0.61 to 2.51$)$ & & & 1.06 (0.49 to 2.31$)$ \\
\hline \multicolumn{5}{|l|}{ Religion } \\
\hline Christian Protestant & Ref. & & & Ref. \\
\hline Christian Orthodox & 0.91 (0.78 to 1.04$)$ & & & $0.93(0.76$ to 1.12$)$ \\
\hline Christian Catholic & 1.01 (0.74 to 1.38$)$ & & & 1.01 (0.73 to 1.40$)$ \\
\hline Muslim & 1.04 (0.87 to 1.25$)$ & & & 1.07 (0.88 to 1.31$)$ \\
\hline Others & $0.70(0.54 \text { to } 0.93)^{*}$ & & & 0.80 (0.60 to 1.07$)$ \\
\hline \multicolumn{5}{|l|}{ Educational level } \\
\hline No formal education & Ref. & & & Ref. \\
\hline Primary education & 1.11 (0.96 to 1.27$)$ & & & $0.99(0.84$ to 1.15$)$ \\
\hline Secondary education & 1.05 (0.90 to 1.22$)$ & & & 0.98 (0.81 to 1.18$)$ \\
\hline College and above & 1.18 (1.00 to 1.39$)$ & & & 1.07 (0.84 to 1.38$)$ \\
\hline \multicolumn{5}{|l|}{ Occupation } \\
\hline Housewife & Ref. & & & Ref. \\
\hline Private employee & $1.06(0.84$ to 1.35$)$ & & & $1.06(0.77$ to 1.47$)$ \\
\hline Government employee & 1.01 (0.89 to 1.16$)$ & & & 0.95 (0.72 to 1.25$)$ \\
\hline Private business & $1.00(0.87$ to 1.16$)$ & & & 1.01 (0.80 to 1.27$)$ \\
\hline Others & $1.14(0.91$ to 1.41$)$ & & & 0.90 (0.69 to 1.16$)$ \\
\hline \multicolumn{5}{|c|}{ Has regular monthly income* } \\
\hline No & Ref. & & & Ref. \\
\hline Yes & 0.95 (0.86 to 1.04$)$ & & & 0.92 (0.75 to 1.13$)$ \\
\hline \multicolumn{5}{|l|}{ Total number of births } \\
\hline One & Ref. & & & Ref. \\
\hline Two or more & $0.76(0.69 \text { to } 0.84)^{*}$ & & & $0.86(0.74$ to 1.02$)$ \\
\hline Antenatal visit during inde & & & & \\
\hline
\end{tabular}


Table 4 Continued

\begin{tabular}{|c|c|c|c|c|}
\hline & Bivariate model & Model I & Model II & Model III \\
\hline Variables & $\mathbf{C} \beta(95 \% \mathrm{Cl})$ & $A \beta(95 \% \mathrm{Cl})$ & A $\beta(95 \% \mathrm{Cl})$ & A $\beta(95 \% \mathrm{Cl})$ \\
\hline No & Ref. & & & Ref. \\
\hline \multicolumn{5}{|l|}{$\begin{array}{l}\text { Experienced complication during index } \\
\text { pregnancy }\end{array}$} \\
\hline No & Ref. & & & Ref. \\
\hline \multicolumn{5}{|l|}{$\begin{array}{l}\text { Experienced complication during index } \\
\text { birth }\end{array}$} \\
\hline No & Ref. & & & Ref. \\
\hline Yes & $1.16(1.05 \text { to } 1.30)^{*}$ & & & $1.16(1.03 \text { to } 1.32)^{*}$ \\
\hline \multicolumn{5}{|l|}{ Referral status on admission } \\
\hline \multicolumn{5}{|l|}{ Gender of main service provider } \\
\hline Female & Ref. & & & Ref. \\
\hline Male & $1.05(0.95$ to 1.16$)$ & & & $1.03(0.931 .16)$ \\
\hline \multicolumn{5}{|l|}{ Type of birth } \\
\hline Vaginal birth & Ref. & & & Ref. \\
\hline Caesarean after trial of vaginal birth & $0.78(0.67 \text { to } 0.90)^{*}$ & & & $0.76(0.63 \text { to } 0.92)^{*}$ \\
\hline Caesarean without trial of vaginal birth & $0.67(0.48 \text { to } 0.95)^{*}$ & & & $0.68(0.47 \text { to } 0.98)^{*}$ \\
\hline \multicolumn{5}{|l|}{ Had intervention for vaginal birth } \\
\hline No & Ref. & & & Ref. \\
\hline \multicolumn{5}{|l|}{ (B) Random effects } \\
\hline \multicolumn{5}{|l|}{ Hospital } \\
\hline Log likelihood & & -798 & -786 & -750 \\
\hline$P$ value & & - & $<0.001$ & $<0.001$ \\
\hline
\end{tabular}

*Bold values are significant at $\mathrm{p}<0.05$.

$\beta$, exponentiated regression coefficient; $A \beta$, adjusted exponentiated regression coefficient; AIC, Akaike's information criterion; $C \beta$, crude exponentiated regression coefficient; ICC, intraclass correlation coefficient.

improvement programmes for all levels of staff and the preservice training of health professionals. Additionally, the high level of mistreatment among women who had complications during childbirth, and assisted vaginal birth might be explained by the fact that several cadres attend women during such events.

According to the Health Workers for Change study conducted in four African countries, structural issues such as shortage/lack of manpower and supplies, and poor working conditions inhibit implementation of change interventions. ${ }^{49}$ According to the Bowser and Hill framework,$^{50}$ structural constraints not only impede change initiatives, they also independently contribute to mistreatment. Thus, the categories of mistreatment that were likely to have been a product of these structural issues were not influenced by the intervention because it lacked a structural dimension.

The fact that there is no private labour room combined with the increased presence of birth companions after the intervention may explain the relative lack of improvement in women's privacy. Adequate preparation and adaptation of labour wards is recommended before operationalising birth companionship in resource-limited contexts. ${ }^{3451}$ Lunze and colleagues reviewed 259 (83 sub-Saharan Africa based) studies and reports of innovative approaches for improving maternal and newborn health, using the lens of WHO's health system building blocks. The review revealed that interventions in one 
health system building block affected other building blocks; the review recommends a system-wide intervention to maximise the effectiveness and sustainability of interventions. ${ }^{52}$ Similarly, WHO also recommends that respectful maternity care should be viewed through the lens of systems thinking when prioritising action areas to improve quality of care. ${ }^{36}$

What makes the Staha study similar to our study is that, no changes in the level of verbal abuse and neglect and discrimination were observed after the intervention. ${ }^{41}$ This might be explained by the fact that ingrained negative and normalised behaviours require time to change and are highly associated with age and experience of service providers, younger and less experienced providers being less supportive during labour. ${ }^{53}$ On the contrary, if a proactive focus on respectful care is provided during preservice training to younger graduates, who are usually motivated for change, it may nurture respectful behaviour. ${ }^{54}$ Additionally, other factors such as uncomfortable working circumstances, overcrowded facilities, space constraints and poorly motivated staff are not only barriers to the implementation of new guidelines ${ }^{55}$ but also contributors to mistreatment. ${ }^{50}$ These factors may have contributed to the steady level of the mistreatment components that did not improve in the current study.

Evidence suggests that women's chosen birth companionship contributes to positive birth outcomes for both the mother and the newborn ${ }^{56}$ and is recommended by the WHO ${ }^{34}$ In this study, among 120 women who wanted to have a birth companion, only $18(15 \%)$ were allowed to have their chosen companion $(11.6 \%$ in pre-intervention vs $23.5 \%$ in post-intervention group). Additionally, $16.7 \%$ ( $14 \%$ in pre-intervention vs $23.5 \%$ in post-intervention group) of those who would have wanted to have a companion were afraid to ask service providers about this. These unexpressed preferences highlight that facilities and service providers should promote companionship rather than wait for the request to come from women. ${ }^{34} 56$ And this should be supported by political commitment, high-level advocacy and operating guidelines. ${ }^{57}$ The proportion of women who reported to have their preference during childbirth in the post-intervention survey was lower than that of pre-intervention survey participants; this may be due to the high proportion of women who had a caesarean birth in the post-intervention survey.

In this study, comparing the number (counts) of mistreatment components women experienced helped to identify the changes in the extent or diversity of mistreatment that would not have been possible to identify by simple prevalence measures. Additionally, treating hospitals as random-effects in the statistical model controls for the impact of other interventions that may have happened around the same time in those facilities. The absence of difference in demographic and obstetric characteristics between women of the two groups (pre-intervention and post-intervention) also adds to the soundness of the statistical analysis used to detect changes in mistreatment. Additionally, where women are admitted in a shared ward, comparing the proportion of women mistreated rather than comparing the counts of mistreatment fails to detect changes that might have resulted after an intervention. This is because, there are components of mistreatment that cannot be totally prevented without major structural changes, for example, provision of adequate space to ensure privacy and confidentiality. ${ }^{40}$

One of the limitations of this study is that the mistreatment components experienced by women repeatedly were counted only once as binary response options (yes/ no) questions were used. This approach fails to capture multiple incidents of mistreatment components experienced by women, for example, how many times a woman was verbally abused. Additionally, it might have also led to the underestimation of the intervention effect size. To overcome such problems, using questions with frequency response options is recommended. A survey of women at their exit, as in this study, is prone to recall bias in acquiring data on multiple incidents; instead, independent observation in the labour room would be more appropriate.$^{58}$ However, observation also has inherent limitations, for example, the Hawthorne effect-service providers modify their behaviour and become less disrespectful because they know they are being observed. Pertaining to the generalisability of findings, because the study was conducted only in three hospitals located in the SNNPR, the findings may not be generalisable to other types of hospitals, health centres and clinics that provide childbirth services in Ethiopia. Additionally, the short washout period and the lack of a control group in this study is a key limitation as it is not possible to attribute with certainty the changes observed to the respectful maternity care intervention.

Finally, we believe that this study being the first to test the effectiveness of a respectful maternity care intervention in Ethiopia, contributes to evidence for further endeavours to improve respectful maternity care specifically, and the quality of childbirth services generally. Thorough implementation studies that are designed to capture macro and micro level contributors to mistreatment need to be conducted to inform evidence-driven actions to eliminate mistreatment during facility-based childbirth in Ethiopia.

\section{CONCLUSIONS}

This study revealed that the childbirth services women received in the study hospitals were characterised by a wide range of mistreatment behaviours and/or health facility conditions. The respectful maternity care intervention tested in this study was accompanied by a reduction in women's experience of mistreatment during facility-based childbirth. Given the variety of factors that lead to mistreatment in health facilities, interventions designed to mitigate mistreatment need to be multidimensional-including demand-side (community level), supply-side (health system level) and policy-level interventions. We believe that this study adds to existing 
knowledge on innovations that can be used to mitigate mistreatment. Further research is needed to investigate the impact and sustainability of health system-level interventions on women's experiences of mistreatment during facility-based childbirth.

\section{Author affiliations}

${ }^{1}$ School of Public Health, College of Medicine and Health Sciences, Hawassa University, Hawassa, Ethiopia

${ }^{2}$ Nossal Institute for Global Health, School of Population and Global Health, University of Melbourne, Melbourne, Victoria, Australia

${ }^{3}$ School of Public Health, College of Health Sciences, Addis Ababa University, Addis Ababa, Ethiopia

${ }^{4}$ Maternal and Child Health Directorate, Ministry of Health, Addis Ababa, Ethiopia

${ }^{5}$ Amref Health Africa in Ethiopia, Addis Ababa, Ethiopia

${ }^{6}$ Institute for Healthcare Improvement, Cambridge, Massachusetts, USA

${ }^{7}$ Division of Global Health Equity, Boston Children's Hospital, Boston, Massachusetts, USA

${ }^{8}$ Division of General Pediatrics, Boston Children's Hospital, Boston, Massachusetts, USA

\section{Twitter Anteneh Asefa @AntenehAsef}

Acknowledgements We would like to pass our heartfelt thanks to experts at the Federal Ministry of Health (Ethiopia), the SNNPR Health Bureau, and Hawassa University College of Medicine and Health Sciences who reviewed the respectful maternity care training manual and coordinated the training sessions. We also extend our appreciation to all participants of the study, service providers and facility administrations for being an active player in the smooth operation of the study. Members of the data collection team also deserve a warm appreciation for their engagement.

Contributors AA conceived the study; AA, AM and MK designed the study, developed data collection tools; AA trained data collectors, coordinated the fieldwork; AA, SA, HM, ETL and SG conducted the intervention; $A A, A M$ and MK analysed the data; $A A, A M$ and MK drafted the manuscript; SA, HM, ETL and SG revised the manuscript for intellectual content. All authors have read and approved the manuscript.

Funding The training of service providers was made possible by support from the Institute of Healthcare Improvement (IHI) through the Federal Ministry of Health, Ethiopia. The primary author of this study is a recipient of the Melbourne Research Scholarship (University of Melbourne), and the Population Health Investing in Research Students' Training (PHIRST) travel grant (Melbourne School of Population and Global Health, University of Melbourne). The contents of this research article only reflect the authors' opinions but do not show interest/s of either of the organisations involved in the funding.

Competing interests None declared.

Patient consent for publication Not required.

Ethics approval Ethics approval was obtained from the Institutional Review Board (Ethics ID: 3-12/12926) located in SNNPR Health Bureau, Ethiopia and the Human Ethics Sub-Committee (Ethics ID: HESC 1750054) at the University of Melbourne, Australia. Permission letter to conduct this study was also granted from the Federal Ministry of Health and SNNPR Health Bureau. A printout of information about the study (plain language statement) prepared in local languages was given to literate study participants, and their written consent was recorded on a separate consent form. For illiterate participants, data collectors read contents of both the plain language statement script and the consent form, sought their verbal consent, and signed the consent form on their behalf in the presence of a witness. All forms used were approved by the ethics committees.

Provenance and peer review Not commissioned; externally peer reviewed.

Data availability statement Data are available upon reasonable request. Reasonable requests can be made to access study data from the corresponding author.

Open access This is an open access article distributed in accordance with the Creative Commons Attribution Non Commercial (CC BY-NC 4.0) license, which permits others to distribute, remix, adapt, build upon this work noncommercially, and license their derivative works on different terms, provided the original work is properly cited, appropriate credit is given, any changes made indicated, and the use is non-commercial. See: http://creativecommons.org/ licenses/by-nc/4.0/.

\section{ORCID iDs}

Anteneh Asefa http://orcid.org/0000-0003-4470-1848

Samson Gebremedhin http://orcid.org/0000-0002-7838-2470

\section{REFERENCES}

1 World Health Organization. Trends in maternal mortality: 2000 to 2017: estimates by who, UNICEF, UNFPA, world bank group and the United nations population division. Geneva, Switzerland: World Health Organization, 2019.

2 Alvarez JL, Gil R, Hernández V, et al. Factors associated with maternal mortality in sub-Saharan Africa: an ecological study. BMC Public Health 2009;9:462.

3 Every Woman Every Child. The global strategy for women's, children's and adolescents' health (2016-2030). Every Woman Every Child 2015

4 Ethiopian Public Health Institute (EPHI) [Ethiopia] and ICF. Ethiopia mini demographic and health survey 2019: key indicators. Rockville, Maryland, USA: EPHI and ICF, 2019.

5 Hailu D, Berhe H. Determinants of institutional childbirth service utilisation among women of childbearing age in urban and rural areas of Tsegedie district, Ethiopia. Midwifery 2014;30:1109-17.

6 Roro MA, Hassen EM, Lemma AM, et al. Why do women not deliver in health facilities: a qualitative study of the community perspectives in South central Ethiopia? BMC Res Notes 2014;7:556.

7 Sipsma H, Thompson J, Maurer L, et al. Preferences for home delivery in Ethiopia: provider perspectives. Glob Public Health 2013:8:1014-26.

8 Tarekegn SM, Lieberman LS, Giedraitis V. Determinants of maternal health service utilization in Ethiopia: analysis of the 2011 Ethiopian demographic and health survey. BMC Pregnancy Childbirth 2014;14:161.

9 Mirkuzie AH. Exploring inequities in skilled care at birth among migrant population in a metropolitan City Addis Ababa, Ethiopia; a qualitative study. Int J Equity Health 2014;13:110.

10 Jackson R, Tesfay FH, Godefay H, et al. Health extension workers and mothers' attitudes to maternal health service utilization and acceptance in Adwa Woreda, Tigray region, Ethiopia. PLoS One 2016;11:e0150747.

11 Wassihun B, Zeleke S. Compassionate and respectful maternity care during facility based child birth and women's intent to use maternity service in Bahir Dar, Ethiopia. BMC Pregnancy Childbirth 2018;18:294.

12 King R, Jackson R, Dietsch E, et al. Barriers and facilitators to accessing skilled birth attendants in afar region, Ethiopia. Midwifery 2015;31:540-6.

13 Bohren MA, Hunter EC, Munthe-Kaas HM, et al. Facilitators and barriers to facility-based delivery in low- and middle-income countries: a qualitative evidence synthesis. Reprod Health 2014;11:71.

14 Tappis H, Koblinsky M, Doocy S, et al. Bypassing primary care facilities for childbirth: findings from a multilevel analysis of skilled birth attendance determinants in Afghanistan. J Midwifery Womens Health 2016;61:185-95.

15 Otis KE, Brett JA. Barriers to hospital births: why do many Bolivian women give birth at home? Rev Panam Salud Publica 2008;24:46-53.

16 Crissman HP, Engmann CE, Adanu RM, et al. Shifting norms: pregnant women's perspectives on skilled birth attendance and facility-based delivery in rural Ghana. Afr J Reprod Health 2013;17:15-26.

17 Dahlberg M, Södergård B, Thorson A, et al. Being perceived as 'a real woman' or following one's own convictions: a qualitative study to understand individual, family, and community influences on the place of childbirth in Busia, Kenya. Cult Health Sex 2015;17:326-42.

18 Kwambai TK, Dellicour S, Desai M, et al. Perspectives of men on antenatal and delivery care service utilisation in rural Western Kenya: a qualitative study. BMC Pregnancy Childbirth 2013;13:134.

19 Kujawski S, Mbaruku G, Freedman LP, et al. Association between Disrespect and abuse during childbirth and women's confidence in health facilities in Tanzania. Matern Child Health J 2015;19:2243-50.

20 Seljeskog L, Sundby J, Chimango J. Factors influencing women's choice of place of delivery in rural Malawi--an explorative study. Afr $J$ Reprod Health 2006;10:66-75.

21 Bruce SG, Blanchard AK, Gurav K, et al. Preferences for infant delivery site among pregnant women and new mothers in northern Karnataka, India. BMC Pregnancy Childbirth 2015;15:49. 
22 Sando D, Abuya T, Asefa A, et al. Methods used in prevalence studies of disrespect and abuse during facility based childbirth: lessons learned. Reprod Health 2017;14:127.

23 Bohren MA, Vogel JP, Hunter EC, et al. The mistreatment of women during childbirth in health facilities globally: a mixed-methods systematic review. PLoS Med 2015;12:e1001847.

24 Banks KP, Karim AM, Ratcliffe HL, et al. Jeopardizing quality at the frontline of healthcare: prevalence and risk factors for disrespect and abuse during facility-based childbirth in Ethiopia. Health Policy Plan 2018;33:317-27.

25 Gebremichael MW, Worku A, Medhanyie AA, et al. Mothers' experience of disrespect and abuse during maternity care in northern Ethiopia. Glob Health Action 2018;11:1465215.

26 Asefa A, Bekele D. Status of respectful and non-abusive care during facility-based childbirth in a hospital and health centers in Addis Ababa, Ethiopia. Reprod Health 2015;12:33.

27 Asefa A, Bekele D, Morgan A, et al. Service providers' experiences of disrespectful and abusive behavior towards women during facility based childbirth in Addis Ababa, Ethiopia. Reprod Health 2018;15:4.

28 Sheferaw ED, Bazant E, Gibson H, et al. Respectful maternity care in Ethiopian public health facilities. Reprod Health 2017;14:60.

29 World Health Organization. The prevention and elimination of disrespect and abuse during facility-based childbirth. World Health Organization, 2014.

30 Vogel JP, Bohren MA, Tunçalp Özge, et al. How women are treated during facility-based childbirth: development and validation of measurement tools in four countries - phase 1 formative research study protocol. Reprod Health 2015;12:60.

31 Rubashkin N, Warnock R, Diamond-Smith N. A systematic review of person-centered care interventions to improve quality of facilitybased delivery. Reprod Health 2018;15:169.

32 Nilvér H, Begley C, Berg M. Measuring women's childbirth experiences: a systematic review for identification and analysis of validated instruments. BMC Pregnancy Childbirth 2017;17:203.

33 Alliance WR. Respectful maternity care: the universal rights of childbearing women. Washington (District of Columbia: White Ribbon Alliance, 2011.

34 World Health Organization. Who recommendations: intrapartum care for a positive childbirth experience. World Health Organization, 2018.

35 World Health Organization. Strategies toward ending preventable maternal mortality (EPMM. World Health Organization, 2015.

36 World Health Organization. Standards for improving quality of maternal and newborn care in health facilities. World Health Organization, 2016.

37 Bohren MA, Mehrtash H, Fawole B, et al. How women are treated during facility-based childbirth in four countries: a cross-sectional study with labour observations and community-based surveys. Lancet 2019;394:1750-63.

38 The Federal Democratic Republic of Ethiopia Ministry of Health Health Sector Transformation Plan: 2015/16 - 2019/20. Addis Ababa, Ethiopia: Federal Ministry of Health, 2015.

39 Abuya T, Ndwiga C, Ritter J, et al. The effect of a multi-component intervention on disrespect and abuse during childbirth in Kenya. BMC Pregnancy Childbirth 2015;15:224.

40 Ratcliffe HL, Sando D, Lyatuu GW, et al. Mitigating disrespect and abuse during childbirth in Tanzania: an exploratory study of the effects of two facility-based interventions in a large public hospital. Reprod Health 2016;13:79.
41 Kujawski SA, Freedman LP, Ramsey K, et al. Community and health system intervention to reduce disrespect and abuse during childbirth in Tanga region, Tanzania: a comparative before-and-after study. PLoS Med 2017:14:e1002341.

42 Asefa A, Morgan A, Bohren MA, et al. Lessons learned through respectful maternity care training and its implementation in Ethiopia: an interventional mixed methods study. Reprod Health 2020;17:103.

43 Charity N, Warren C, Abuya T, et al. Promoting respectful maternity care a training guide for facility-based workshops. New York: Population Council, 2015.

44 Maternal and Child Health Integrated Program. Respectful maternity care workshop: learning resource package. Maternal and Child Health Integrated Program, 2013.

45 White Ribbon Alliance. Respectful maternity care: a Nigeria focused health workers' training guide. Washington, DC: Futures Group, Health Policy Project, 2015

46 United Nations. Universal Declaration of human rights: United nations, 1948. Available: http://www.un.org/en/universal-declarationhuman-rights/

47 United Nations General Assembly. Technical guidance on the application of a human rightsbased approach to the implementation of policies and programmes to reduce preventable maternal morbidity and mortality. United Nations 2012.

48 Chang Y-S, Coxon K, Portela AG, et al. Interventions to support effective communication between maternity care staff and women in labour: a mixed-methods systematic review. Midwifery 2018;59:4-16.

49 Fonn S, Mtonga AS, Nkoloma HC, et al. Health providers' opinions on provider-client relations: results of a multi-country study to test health workers for change. Health Policy Plan 2001;16 Suppl 1:19-23.

50 Bowser D, Hill K. Exploring evidence for Disrespect and abuse in Facility-Based Childbirth-A landscape analysis of the global situation of abuse and disrespect in maternity care. USAID, Traction Project 2010.

51 Miller S, Abalos E, Chamillard M, et al. Beyond too little, too late and too much, too soon: a pathway towards evidence-based, respectful maternity care worldwide. Lancet 2016;388:2176-92.

52 Lunze K, Higgins-Steele A, Simen-Kapeu A, et al. Innovative approaches for improving maternal and newborn health--A landscape analysis. BMC Pregnancy Childbirth 2015;15:337.

53 Barrett SJ, Stark MA. Factors associated with labor support behaviors of nurses. J Perinat Educ 2010;19:12-18.

54 Dynes MM, Twentyman E, Kelly L, et al. Patient and provider determinants for receipt of three dimensions of respectful maternity care in Kigoma region, Tanzania-April-July, 2016. Reprod Health 2018;15:41.

55 Spallek H, Song M, Polk DE, et al. Barriers to implementing evidence-based clinical guidelines: a survey of early adopters. J Evid Based Dent Pract 2010;10:195-206.

56 Hodnett ED, Gates S, Hofmeyr GJ, et al. Continuous support for women during childbirth. Cochrane database of systematic reviews 2013.

57 Sharma G, Mathai M, Dickson KE, et al. Quality care during labour and birth: a multi-country analysis of health system bottlenecks and potential solutions. BMC Pregnancy Childbirth 2015;15 Suppl 2:S2.

58 Bohren MA, Vogel JP, Fawole B, et al. Methodological development of tools to measure how women are treated during facility-based childbirth in four countries: labor observation and community survey. BMC Med Res Methodol 2018;18:132. 